\title{
Predicting Daily Physical Activity in Patients with Chronic Obstructive Pulmonary Disease
}

\author{
Arnoldus J. R. van Gestel ${ }^{1,2 *}$, Christian F. Clarenbach ${ }^{1}$, Anne C. Stöwhas ${ }^{1}$, Valentina A. Rossi ${ }^{1}$, \\ Noriane A. Sievi ${ }^{1}$, Giovanni Camen ${ }^{1}$, Erich W. Russi ${ }^{1,3}$, Malcolm Kohler ${ }^{1,3}$
}

1 Pulmonary Division, University Hospital of Zurich, Zurich, Switzerland, 2 Department of Health, Zurich University of Applied Sciences, Winterthur, Switzerland, 3 Center for Integrative Human Physiology, University of Zurich, Zurich, Switzerland

\begin{abstract}
Background: Objectively measuring daily physical activity $(P A)$ using an accelerometer is a relatively expensive and timeconsuming undertaking. In routine clinical practice it would be useful to estimate PA in patients with chronic obstructive pulmonary disease (COPD) with more simple methods.

Objectives: To evaluate whether PA can be estimated by simple tests commonly used in clinical practice in patients with COPD.

Methods: The average number of steps per day was measured for 7 days with a SenseWear Pro ${ }^{\mathrm{TM}}$ accelerometer and used as gold standard for PA. A physical activity level (PAL) of $<1.4$ was considered very inactive. Univariate and multivariate analyses were used to examine the relationship between the 6-minute walking distance (6MWD), the number of stands in the Sit-to-Stand Test (STST), hand-grip strength and the total energy expenditure as assessed by the Zutphen Physical Activity Questionnaire (TEE $\mathrm{ZPAQ}_{\mathrm{P}}$ ). ROC curve analysis was used to identify patients with an extremely inactive lifestyle (PAL $\left.<1.4\right)$.

Results: In 70 patients with COPD (21 females) with a mean [SD] FEV 1 of 43.0 [22.0] \%predicted, PA was found to be significantly and independently associated with the 6MWD $(r=0.69,95 \% \mathrm{Cl} 0.54$ to $0.80, p<0.001)$, STST $(r=0.51,95 \% \mathrm{Cl}$ 0.31 to $0.66, p=0.001)$ and TEEZPAQ $(r=0.50,95 \% \mathrm{Cl} 0.30$ to $0.66, p<0.001)$ but not with hand-grip strength. However, ROC curve analysis demonstrated that these tests cannot be used to reliably identify patients with an extremely inactive lifestyle.

Conclusions: In patients with COPD simple tests such as the 6-Minute Walk Test, the Sit-to-Stand Test and the Zutphen Physical Activity Questionnaire cannot be used to reliably predict physical inactivity.
\end{abstract}

Citation: van Gestel AJR, Clarenbach CF, Stöwhas AC, Rossi VA, Sievi NA, et al. (2012) Predicting Daily Physical Activity in Patients with Chronic Obstructive Pulmonary Disease. PLoS ONE 7(11): e48081. doi:10.1371/journal.pone.0048081

Editor: Rory Edward Morty, University of Giessen Lung Center, Germany

Received May 28, 2012; Accepted September 20, 2012; Published November 2, 2012

Copyright: (C) 2012 van Gestel et al. This is an open-access article distributed under the terms of the Creative Commons Attribution License, which permits unrestricted use, distribution, and reproduction in any medium, provided the original author and source are credited.

Funding: The authors have no support or funding to report.

Competing Interests: The authors have declared that no competing interests exist.

*E-mail: vrns@zhaw.ch

\section{Introduction}

Physical inactivity in daily life is a prominent feature in patients with chronic obstructive pulmonary disease (COPD) [1-4]. Reduced physical fitness may lead to a shift in patients' lifestyle with low daily physical activity levels (PA) inducing a vicious circle of decreased exercise tolerance, which in turn further reduces activity levels and increases social isolation and depression [5].

The Global Initiative for Chronic Obstructive Lung Disease (GOLD) states that increased participation in physical and social activities of daily living should be among the pertinent clinical issues in the management of patients with COPD [6]. Due to the impact of impaired PA on the health status in patients with COPD, accurately estimating the amount and intensity of physical activity in daily life is considered very important [7].

Physical performance in patients with COPD has been assessed mostly by direct observation, by subjective methods such as selfreported questionnaires and diaries [8] and by objective methods such as accelerometers, pedometers [9] and physical fitness tests such as the 6-Minute Walk Test (6MWT), the Sit-to-Stand Test (STST) [10] and the Hand-grip strength Test [11]. Objectively measuring $P A$ using accelerometry seems to be the most accurate fieldbased estimate of $P A$ [12], however, it is a relatively expensive and time-consuming undertaking. In routine clinical practice it would be useful to estimate PA with less expensive, less time-consuming and more practical methods. Therefore, the aim of the present study was to investigate if the 6MWT, STST, Hand-grip strength Test and Zutphen Physical Activity Questionnaire (ZPAQ) can accurately predict daily PA in patients with COPD.

\section{Study Subjects}

Patients with COPD referred to the Pulmonary Division, University Hospital of Zurich, Switzerland between January 2010 and August 2011 were considered for participation in the study. The inclusion criteria for patients were: male/female subjects aged 40-75 yrs and confirmed COPD according to GOLD-guidelines. The exclusion criteria were: acute or recent (within last 6 weeks) exacerbation of COPD according to GOLD-guidelines, patients 
on long-term oral corticosteroids or morphine medication and mental or physical disability precluding informed consent or compliance with the protocol. The study was approved by the Research Ethics Committee of the University Hospital of Zurich, Switzerland (EK-1734) and written informed consent was obtained from all patients.

\section{Methods}

\section{Pulmonary Function}

Spirometry, whole body plethysmography and diffusing capacity measurements were performed according to the American Thoracic Society (ATS) and the European Respiratory Society (ERS) guidelines with a commercially available system $[12,13]$.

\section{Daily Physical Activity, Accelerometry}

A multisensor accelerometer (SenseWear Pro ${ }^{\mathrm{TM}}$ armband; BodyMedia, Inc., Pittsburgh, PA, USA) which is worn on the upper right arm was used. The device estimates energy expenditure (EE) using measurements from a biaxial accelerometer and sensors that quantify galvanic skin response, heat flux and skin temperature. The biaxial accelerometer records the number of steps and the duration of physical activity (PAD) [14]. The physical activity level (PAL) was calculated by dividing the total daily energy expenditure by energy expenditure during sleep [15]. A PAL $\geq 1.70$ defines a moderate to extremely active person, 1.40-1.69 defines a sedentary person, and $<1.40$ defines an extremely inactive person [15-17]. The patients were instructed to wear the accelerometer continuously during 7 consecutive days, except when bathing or showering.

\section{6-Minute Walking Test}

Patients performed the $6 \mathrm{MWT}$ following pulmonary function testing. 6MWT distance was measured according to the guidelines of the American Thoracic Society (ATS) [18]. The 6MWT was performed on a 30-meter indoor track by an experienced investigator using standardized encouragement strategy. None of the patients used a walking aid in daily life or during the test.

\section{Sit-to-Stand Test}

A standard chair (height $46 \mathrm{~cm}$ ) with no arm supports was used. The patients were instructed to stand up from and sit down on the chair with no support from the hands, repeating the procedure as many times as possible for a duration of one minute at a patientdefined pace [10].

\section{Hand-grip Strength Test}

Skeletal muscle strength of the hand was estimated based on handgrip strength of the dominant hand measured with a dynamometer as described elsewhere (Hand-Dynamometer Bremshey; Accell Fitness, Almere, Netherlands) [19].

\section{Zutphen Physical Activity Questionnaire}

The ZPAQ has been used to characterize PA in daily life in patients with COPD [20]. The ZPAQ [21] is a self-reported physical activity questionnaire and addresses the frequency and duration of the patients̀ activities of the previous week; the average amount of time spent weekly on "homely activities", "gardening", "hobbies" and the average amount of time spent monthly on "jobs" and "sports". According to the frequency, intensity and duration of these activities, a summary Metabolic Equivalent (MET) score expressed in $\mathrm{kcal} / \mathrm{kg} /$ day is calculated based on an intensity code for each activity, as described by Durrin and
Passmore [22] and the Minnesota leisure-time physical activity questionnaire as described by Jacobs [23] and Folsom [24].

\section{Data Analysis}

A statistical software package was used for all calculations (SPSS for Windows, version 11.0, SPSS Inc., Chicago, IL, USA). Descriptive data for continuous variables are expressed as mean and standard deviation. Univariate (Pearson's correlation) and multivariate analyses were performed to evaluate the association between PA (the average number of steps per day) and the 6MWT, STST, Hand-grip Test as well as the ZPAQ. The multivariate analysis included the average number of steps per day derived from accelerometry as the dependent and either 6MWT, STST, Hand-grip strength Test or ZPAQ as well as partial pressure of oxygen $\left(\mathrm{PaO}_{2}\right)$, forced expiratory volume in one second $\left(\mathrm{FEV}_{1}\right)$, age and body mass index (BMI) as independent variables. ROC curve analysis was used to compare the predictive ability of the 6MWT, STST, Handgrip strength Test and the ZPAQ and to determine the most useful threshold to identify subjects with extremely low physical activity $(\mathrm{PAL}<1.4)$. A p-value of $<0.05$ was considered to indicate statistical significance.

\section{Results}

\section{Study Profile and Patients' Characteristics}

Figure 1 shows the study profile. Seventy patients with COPD agreed to take part and were included in the study. Anthropometrical characteristics and pulmonary function data of the patients are presented in table 1. COPD was mild (GOLD I) in $23.9 \%$, moderate (GOLD II) in $8.5 \%$, severe (GOLD III) in $31.0 \%$, and very severe (GOLD IV) in $36.6 \%$ of the patients.

\section{Physical Activity}

Data describing physical activity are summarized in table 2 . The mean PAL of the patients was $1.47(0.23) ; 42.2 \%$ of the patients had an extremely inactive lifestyle (PAL $<1.4), 40.2 \%$ of the patients had a sedentary lifestyle (PAL 1.40-1.69) and $17.6 \%$ of the patients were classified as moderate to vigorously active $(\mathrm{PAL} \geq 1.70)$. Mean total energy expenditure $\left(\mathrm{TEE}_{\mathrm{ACC}}\right)$ estimated by accelerometry was higher than total energy expenditure $\left(\mathrm{TEE}_{\mathrm{ZPAQ}}\right)$ assessed by the self-reported physical activity questionnaire: 2200 [478] and 1292 [1093] kcal/day, respectively (mean difference 922 [95] kcal/day, 95\% CI 703 to $1141 \mathrm{kcal} /$ day, $\mathrm{p}<0.001)$.

\section{Relationship between Accelerometry and Physical Performance Tests}

There was a statistically significant positive correlation between the average number of steps per day measured by accelerometry and the 6 -minute walking distance $(6 \mathrm{MWD})$, the number of stands during the STST, the metabolic equivalent as measured by accelerometry (MET), the total energy expenditure estimated by accelerometry $\left(\mathrm{TEE}_{\mathrm{ACC}}\right)$, the time spent per day on activities demanding more than 3 metabolic equivalents (TSA) and the total energy expenditure as assessed by the selfreported physical activity questionnaire (TEE $\mathrm{ZPAQ}_{\mathrm{Z}}$ ) (table 3, figure 2).

The results of the multivariate analyses are shown in table 4 . The average number of steps per day was found to be independently associated with the $6 \mathrm{MWD}$, STST and TEE $\mathrm{ZPAQ}$. By using $6 \mathrm{MWD}$ in the multivariate analysis $49.9 \%$ of the variance in daily PA could be explained by the model (table 4). STST and 


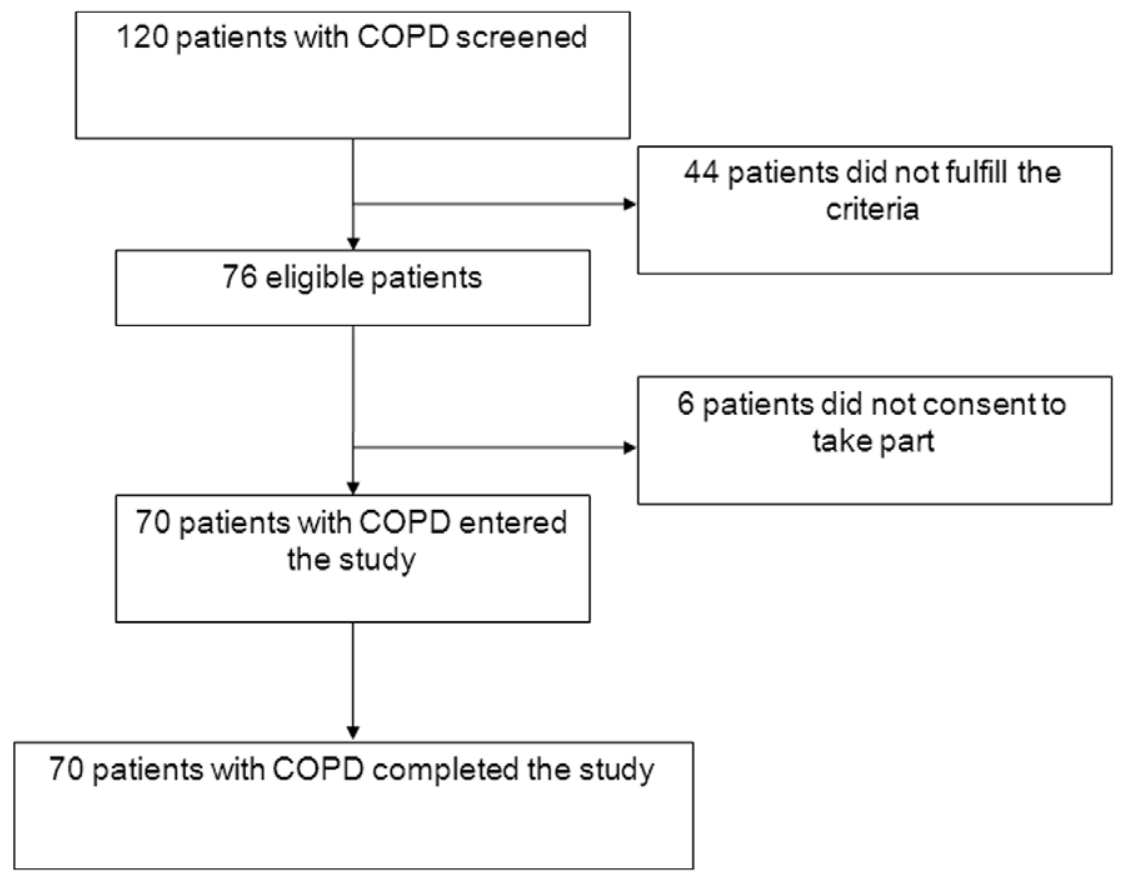

Figure 1. Study profile.

doi:10.1371/journal.pone.0048081.g001

TEE $_{Z P A Q}$ explained $51.7 \%$ and $47.9 \%$ of the variance in $P A$, respectively (table 4 ).

\section{Prediction of Extreme Inactivity}

ROC curve analysis revealed that only the 6MWT had modest predictive capacity (area under the curve 0.68). Corresponding analyses for the STST and the ZPAQ showed an area under the

Table 1. Anthropometrics and Pulmonary Function.

\begin{tabular}{|c|c|}
\hline \multicolumn{2}{|l|}{ Variable } \\
\hline \multicolumn{2}{|l|}{ Anthropometrics } \\
\hline Subjects (n) & 70 \\
\hline Female/male & $21 / 49$ \\
\hline Age (years) & $62.4(7.4)$ \\
\hline BMI $\left(\mathrm{kg} / \mathrm{m}^{2}\right)$ & $25.0(7.7)$ \\
\hline \multicolumn{2}{|l|}{ Pulmonary function } \\
\hline $\mathrm{FEV}_{1}(\mathrm{I})$ & $1.2(0.7)$ \\
\hline $\mathrm{FEV}_{1}$ (\% predicted) & $43.0(22.0)$ \\
\hline $\mathrm{FEV}_{1} / \mathrm{FVC}$ (ratio) & $43.6(15.0)$ \\
\hline DLCO (\% predicted) & $48.2(23.6)$ \\
\hline TLC (\% predicted) & $116.8(20.9)$ \\
\hline RV/TLC (ratio) & $0.57(0.14)$ \\
\hline $\mathrm{PaO}_{2}(\mathrm{kPa})$ & $9.2(1.9)$ \\
\hline $\mathrm{PaCO}_{2}(\mathrm{kPa})$ & $5.2(0.8)$ \\
\hline
\end{tabular}

Values are presented as mean (SD). BMI: body mass index; $\mathrm{FEV}_{1}$ : forced expiratory volume in one second; $F E V_{1} / F V C$ ratio: forced expiratory volume in $1 \mathrm{sec}\left(\mathrm{FEV}_{1}\right)$ expressed as percent of FVC; DLCO: diffusion capacity for carbon monoxide; TLC: total lung capacity; RV/TLC: residual volume/total lung capacity ratio; $\mathrm{PaO}_{2}$ : partial pressure of oxygen; $\mathrm{PaCO}_{2}$ : partial pressure of carbon dioxide.

doi:10.1371/journal.pone.0048081.t001 curve of 0.31 and 0.43 respectively. Therefore, only the 6MWD was used for further analysis and $425 \mathrm{~m}$ appeared as the most useful cut-off point to predict a very inactive lifestyle with a positive and negative predictive value of 0.46 and 0.65 respectively (likelihood ratio of 1.20).

Table 2. Physical Performance.

\begin{tabular}{|c|c|}
\hline \multicolumn{2}{|l|}{ Variable } \\
\hline \multicolumn{2}{|l|}{ Physical fitness } \\
\hline 6MWD (m) & $384.3(136.4)$ \\
\hline 6MWD (\% predicted) & $63.4(21.2)$ \\
\hline Sit-to-Stand Test (n) & $20(6)$ \\
\hline Hand-grip Test (kg) & $37.3(10.2)$ \\
\hline \multicolumn{2}{|c|}{ Daily physical activity by accelerometry } \\
\hline PAL (ratio) & $1.47(0.23)$ \\
\hline MET (kcal/h/kg) & $1.2(0.22)$ \\
\hline $\mathrm{TEE}_{\mathrm{ACC}}(\mathrm{kcal} / \mathrm{day})$ & $2200(478)$ \\
\hline TSA $>3$ METs (min/day) & $55.2(62.23)$ \\
\hline Steps/day (n) & $5272(3319)$ \\
\hline \multicolumn{2}{|c|}{ Questionnaire-based daily physical activity } \\
\hline Stairs per week (n) & $7.6(9.4)$ \\
\hline Total (MET/week) & $118.1(96.1)$ \\
\hline TEE $_{\text {ZPAQ }}$ (kcal/day) & $1292(1093)$ \\
\hline
\end{tabular}

Values are presented as mean (SD). PAL: physical activity level; MET: metabolic equivalent; $T E_{A C C}$ : total energy expenditure per day as assessed by accelerometry; TSA $>3$ METs: time spend per day in activities demanding more than 3 metabolic equivalents; steps/day: number of steps per day; $\mathrm{TEE}_{\mathrm{ZPAO}}$ : total energy expenditure per day as assessed by the Zutphen Physical Activity Questionnaire.

doi:10.1371/journal.pone.0048081.t002 

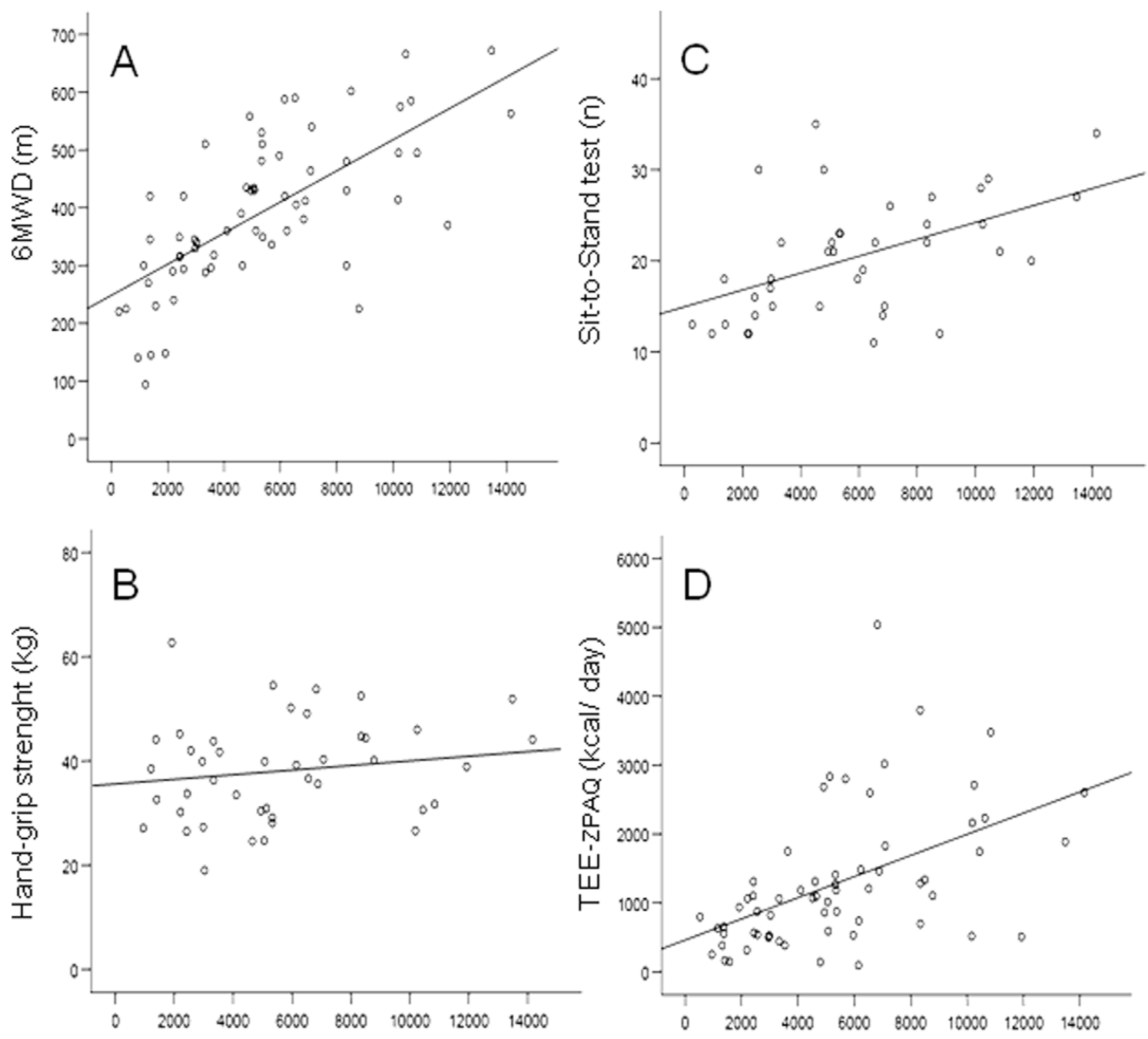

Steps-per-day (n)

Steps-per-day (n)

Figure 2. Scatterplots showing the relationship between PA (the average number of steps per day, $n$ ) and A: the 6-Minute Walking Distance, $6 \mathrm{MWD}(r=0.69,95 \% \mathrm{Cl} 0.54$ to $0.80, p<0.001)$, B: hand-grip strength ( $r=0.21,95 \% \mathrm{Cl}-0.03$ to $0.42, p=0.190)$, C: Sit-toStand Test, STST $(r=0.51,95 \% \mathrm{Cl} 0.31$ to $0.66, p=0.001)$ and $D$ : the total energy expenditure as assessed by the Zutphen Physical Activity Questionnaire, $\operatorname{TEE}_{\mathrm{ZPAQ}}(\mathrm{r}=0.50,95 \% \mathrm{Cl} 0.30$ to $0.66, \mathrm{p}<0.001)$. doi:10.1371/journal.pone.0048081.g002

\section{Relationship between Disease Severity and Physical Performance}

Statistically significant positive correlations were found between $F E V_{1}$ (\%predicted) and 6MWD ( $\mathrm{r}=0.60,95 \%$ CI 0.43 to $0.73, \mathrm{p}<0.001)$, the average number of steps per day $(\mathrm{r}=0.50,95 \%$ CI 0.30 to $0.66, \mathrm{p}<0.001)$, STST $(\mathrm{n})(\mathrm{r}=0.37,95 \%$ CI 0.15 to 0.56 , $\mathrm{p}=0.014), \mathrm{TEE}_{\mathrm{ACC}}(\mathrm{r}=0.32,95 \%$ CI 0.09 to $0.52, \mathrm{p}=0.011)$ and $\mathrm{TEE}_{\text {ZPAQ }}(\mathrm{r}=0.31,95 \%$ CI 0.28 to $0.44, \mathrm{p}=0.012$ ) (figure 3 ) but not with hand-grip strength $(\mathrm{r}=0.059,95 \%$ CI -0.18 to 0.29 , $\mathrm{p}=0.696)$.

\section{Discussion}

Methods capable of accurately estimating PA levels and thus quantifying the level of disability are becoming an increasingly important clinical issue in the management of patients with COPD. Accelerometry is the most accepted method used to measure PA [14]. We investigated the usefulness of less expensive, less timeconsuming and more practical methods and found that the 6minute walking distance (6MWD), the number of stands in the STST and the total energy expenditure as assessed by the ZPAQ were independently associated with the average number of steps per day. Despite this, we found that these tests cannot be used to 
Table 3. Correlations with Average Steps per Day.

\begin{tabular}{|c|c|c|c|}
\hline Variable & Coefficient $\mathbf{r}$ & $95 \% \mathrm{Cl}$ & p-Value \\
\hline \multicolumn{4}{|l|}{ Performance tests } \\
\hline 6MWD (m) & 0.69 & $0.54-0.80$ & $<0.001$ \\
\hline Sit-to-Stand Test (n) & 0.51 & $0.31-0.66$ & 0.001 \\
\hline Hand-grip strength Test (kg) & 0.21 & $-0.03-0.42$ & 0.19 \\
\hline \multicolumn{4}{|l|}{$\begin{array}{l}\text { Performance-based daily } \\
\text { physical activity }\end{array}$} \\
\hline MET (kcal/h/kg) & 0.58 & $0.40-0.72$ & $<0.001$ \\
\hline $\mathrm{TEE}_{\mathrm{ACC}}$ (kcal/day) & 0.46 & $0.25-0.63$ & $<0.001$ \\
\hline TSA > 3METs (min/day) & 0.48 & $0.28-0.64$ & $<0.001$ \\
\hline \multicolumn{4}{|l|}{$\begin{array}{l}\text { Questionnaire-based daily } \\
\text { physical activity }\end{array}$} \\
\hline Stairs per week (n) & 0.39 & $0.17-0.57$ & 0.001 \\
\hline TEE $_{\text {ZPAQ }}$ (kcal/day) & 0.50 & $0.30-0.66$ & $<0.001$ \\
\hline \multicolumn{4}{|c|}{$\begin{array}{l}\text { Correlation is expressed as Pearson's correlation coefficient. MET: metabolic } \\
\text { equivalent; } \text { TEE }_{\text {Acc: }} \text { total energy expenditure per day as assessed by } \\
\text { accelerometry; TSA > } 3 \text { METs: time spend per day in activities demanding more } \\
\text { than } 3 \text { metabolic equivalents; TEE } \\
\text { aspese total energy expenditure per day as } \\
\text { doi:10.1371/journal.pone. } 0048081 . t 003\end{array}$} \\
\hline
\end{tabular}

accurately predict an extremely inactive lifestyle in patients with COPD.

In clinical practice, the $6 \mathrm{MWT}$ is widely used to assess physical fitness in patients with COPD [25]. The 6MWT is easy to perform, has been standardized [18], and is well tolerated by patients with COPD. Furthermore, the 6MWD has been suggested to be an independent predictor of mortality in patients with COPD [26]. Compared to the age, sex, height and weight matched normal values of Troosters and colleagues [29] the mean $6 \mathrm{MWD}$ of our patients was $63.4 \%$ predicted. Several authors have proposed that $6 \mathrm{MWD}$ and PA as assessed by accelerometry are associated in patients with COPD [9,27-31]. The findings of the current study corroborate these earlier results, however, ROC curve analysis revealed that the 6MWT cannot be used to reliably predict a very inactive lifestyle.

The STST is an accepted measure of functional status in both elderly people [32] and in patients with COPD [33,34]. The number of stands during the STST correlates with the BODE Index [26] and is considered a predictor of disease severity [34]. The test is almost self- explanatory and consumes less time, is better tolerated by patients and produces less hemodynamical stress compared to the 6MWT [34]. In the current study, we found that the number of stands during the STST was correlated with $\mathrm{FEV}_{1}$ and independently associated with PA. However, $R O C$ curve analysis revealed that the STST cannot be used to predict a very inactive lifestyle.

Pitta and colleagues stated [9] that PA could be better predicted by a "global" or "integrative" test (e.g. 6MWT) rather than by tests focused on single components of physical functioning, such as lung function or muscle strength. In accordance, we found that peripheral muscle strength of the hand as measured by the Handgrip strength test was not associated with daily PA and thus may not be used to estimate daily physical activity.

The ZPAQ can be self-completed in 15 minutes and showed a good internal reliability, test-retest reliability and validity in a general population of elderly men [24]. In the current study, we found that the daily energy expenditure as assessed by the ZPAQ $\left(\mathrm{TEE}_{\mathrm{ZPAQ}}\right)$ was independently associated with PA. This is
Table 4. Multiple Regression Analysis of Predictors of Physical Activity (Steps per Day).

\begin{tabular}{|c|c|c|c|c|c|}
\hline Model 1 & $\begin{array}{l}\text { Coefficient } \\
\text { B }\end{array}$ & $\begin{array}{l}\text { Std. } \\
\text { Error }\end{array}$ & $\begin{array}{l}\text { Coefficient } \\
\beta\end{array}$ & $\mathbf{t}$ & p-Value \\
\hline Residual & -2221.65 & 4172.01 & & -0.53 & 0.596 \\
\hline 6MWD (m) & 14.67 & 3.40 & 0.57 & 4.32 & $<0.001$ \\
\hline $\mathrm{PaO}_{2}(\mathrm{kPa})$ & 128.29 & 194.85 & 0.069 & 0.66 & 0.513 \\
\hline $\begin{array}{l}\mathrm{FEV}_{1} \\
\text { (\%predicted) }\end{array}$ & 24.13 & 20.01 & 0.16 & 1.21 & 0.233 \\
\hline Age (years) & 8.37 & 45.37 & 0.019 & 0.18 & 0.854 \\
\hline BMI $\left(\mathrm{kg} / \mathrm{m}^{2}\right)$ & -37.83 & 62.70 & -0.063 & -0.60 & 0.549 \\
\hline \multicolumn{6}{|l|}{ Model 2} \\
\hline Residual & 817.65 & 5829.85 & & 0.14 & 0.889 \\
\hline STST (n) & 155.38 & 73.15 & 0.28 & 2.12 & 0.041 \\
\hline $\mathrm{PaO}_{2}(\mathrm{kPa})$ & 327.9 & 307.06 & 0.16 & 1.07 & 0.293 \\
\hline $\begin{array}{l}\text { FEV }_{1} \\
\text { (\%predicted) }\end{array}$ & 70.1 & 25.28 & 0.41 & 2.77 & 0.009 \\
\hline Age (years) & -85.14 & 61.48 & -0.18 & -1.39 & 0.175 \\
\hline BMI $\left(\mathrm{kg} / \mathrm{m}^{2}\right)$ & 26.05 & 83.82 & 0.039 & 0.31 & 0.758 \\
\hline \multicolumn{6}{|l|}{ Model 3} \\
\hline Residual & 1448.95 & 3726.93 & & 0.39 & 0.699 \\
\hline $\begin{array}{l}\text { TEE }_{\text {ZPAQ }} \\
\text { (kcal/day) }\end{array}$ & 1.52 & 0.36 & 0.46 & 4.28 & $<0.001$ \\
\hline $\mathrm{PaO}_{2}(\mathrm{kPa})$ & 243.33 & 192.16 & 0.13 & 1.27 & 0.211 \\
\hline $\begin{array}{l}\text { FEV }_{1} \\
\text { (\%predicted) }\end{array}$ & 59.61 & 16.28 & 0.41 & 3.66 & 0.001 \\
\hline Age (years) & 21.45 & 46.04 & 0.05 & 0.47 & 0.643 \\
\hline BMI $\left(\mathrm{kg} / \mathrm{m}^{2}\right)$ & -161.24 & 60.38 & -0.28 & -2.67 & 0.010 \\
\hline
\end{tabular}

6MWT: 6-Minute Walk Test; STST: Sit-to-Stand Test; TEE $\mathrm{ZPAQ}_{\text {: }}$ total energy expenditure per day as assessed by the Zutphen Physical Activity

Questionnaire; $\mathrm{PaO}_{2}$ : partial pressure of oxygen; $\mathrm{FEV}_{1}$ : forced expiratory volume in one second; BMI: body mass index.

doi:10.1371/journal.pone.0048081.t004

interesting, as the use of self-reported activity questionnaires has been challenged as a poor measure of actual PA in daily life [35] due to limited validity and reliability [36] as well as due to poor correlation with objectively quantified PA in patients with COPD $[37,38]$. It has been speculated that the weak association between self-reported activity and actual PA is due to impaired memory [39], the possibility of misreporting activity time [40] or unnoticed movements [37]. In addition, the effect of social desirability and social approval on self-reports may also influence accurate recall of the type, intensity, frequency and duration of daily PA [41]. Although there was an independent association between $\mathrm{TEE}_{\mathrm{ZPAQ}}$ and PA, patients with COPD seemed to underestimate their daily PA level (figure 3). On the other hand, this discrepancy can also be explained by the fact that accelerometry overestimates TEE [42]. In addition, we found that the ZPAQ cannot be used to identify extremely inactive patients. Thus we conclude that self-reported physical activity needs to be interpreted with care when assessing the activity level of COPD patients.

In this study, we found significant positive correlations between the severity of COPD $\left(F E V_{1}\right)$ and the average number of steps per day, 6MWD, Sit-to-Stand Test, $\mathrm{TEE}_{\mathrm{ACC}}$ and TEE $\mathrm{ZPAO}_{\text {. The }}$ findings suggest that with advanced airflow limitation and disease severity, both daily PA and physical fitness are impaired in patients with COPD. In a recently published study by Garcia- Aymerich and colleagues [43], physical activity of less than 60 minutes per day 


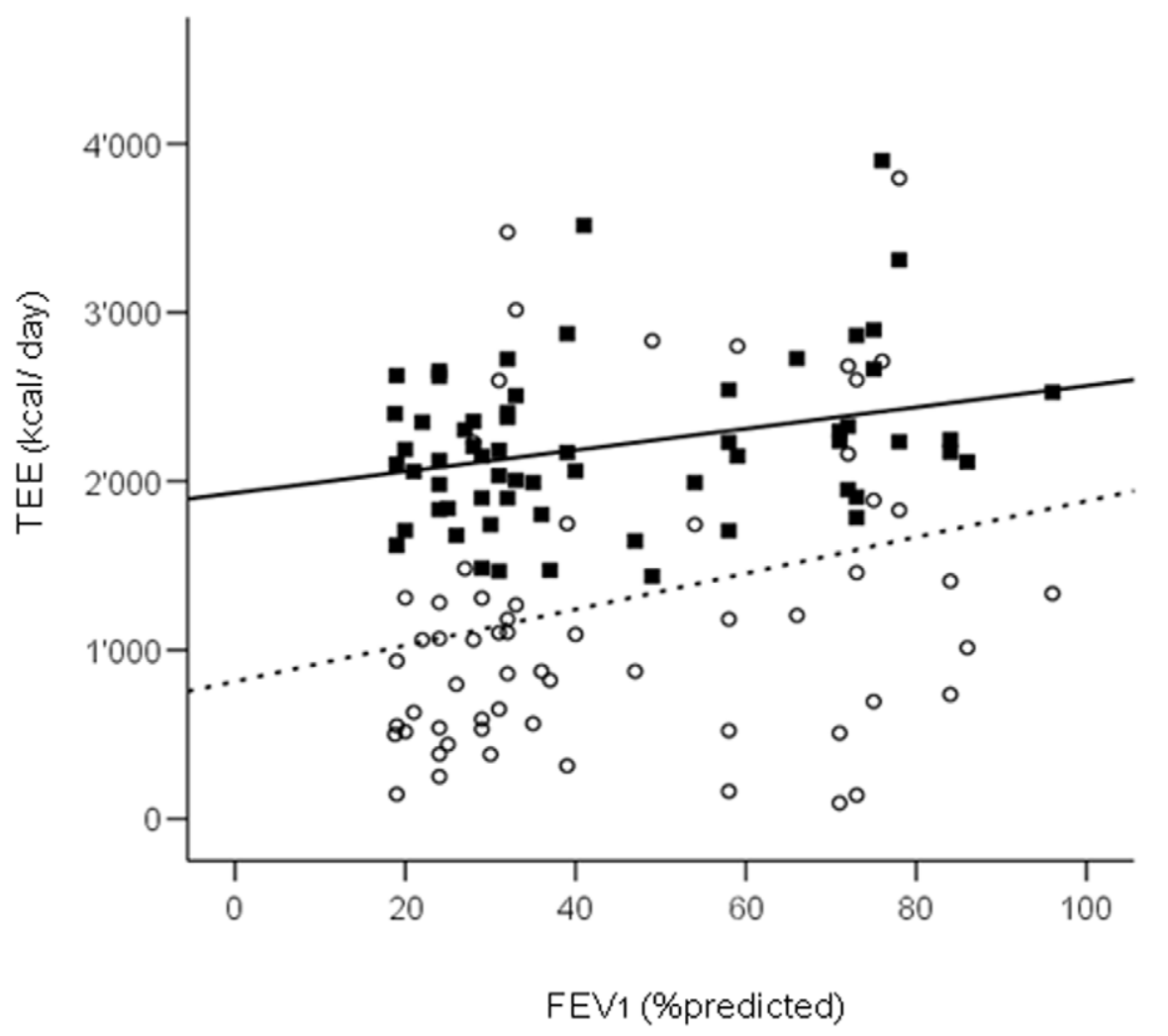

Figure 3. Scatterplots showing the relationship between $\mathrm{FEV}_{1}$ (\%predicted) and the total energy expenditure as assessed by accelerometry, $\mathrm{TEE}_{\mathrm{ACC}}$ (black squares) $(r=0.32,95 \% 0.09$ to $0.52, \mathrm{p}=0.011)$ and by the Zutphen Physical Activity Questionnaire, TEE $_{Z P A Q}$ (white dots) $(r=0.31,95 \% \mathrm{Cl} 0.81$ to $0.51, p=0.012)$, respectively. Patients with COPD seem to underestimate their daily PA level. doi:10.1371/journal.pone.0048081.g003

was considered a risk factor for hospital readmission in patients with COPD. In the current study, we found that $70 \%$ of our patients can be considered "at risk". Furthermore we found that $86 \%$ of our patients walked considerably less than the 10,000 steps per day recommended for health promotion $[44,45]$ and $82.4 \%$ of the patients had a sedentary to extremely inactive lifestyle [15-17]. These results show that patients with COPD should be actively encouraged to be more active and take part in physical fitness programmes. Interestingly, compared to the PA values, the results of the 6MWT seem to be more optimistic in absolute terms. This discrepancy may be due to external factors, such as effort spent, motivation and the instructions and the encouragement given to the subjects participating in a $6 \mathrm{MWT}$ in contrast to their usual activity in daily life. In addition, it may be postulated that PAL in patients with COPD are directly linked to depressive syndromes and anxiety [46].

The present study has certain limitations that need to be taken into account. First, the number of subjects is quite small given the variance in data. Second, it is difficult to identify a gold standard measure of daily PA against which to assess the accuracy of

\section{References}

1. Kapella MC, Larson JL, PatelMK CoveyMK, Berry JK (2006) Subjective fatigue, influencing variables, and consequences in chronic obstructive pulmonary disease. Nurs Res 55(1): 10-17.

2. Donaldson GC, Wilkinson TMA, Hurst JR, Perera WR, Wedzicha JA (2005) Exacerbations and time spent outdoors in chronic obstructive pulmonary disease. Am J Respir Crit Care Med 171: 446-452.

3. Decramer M, Gosselink R, Troosters T (1997) Muscle weakness is related to utilization of health care resources in COPD patients. Eur Respir J 10: 417-423. different methods. The methods used in this study have different outcomes, with accuracy assessed in various ways. However, the SenseWear Pro ${ }^{\mathrm{TM}}$ armband used in this study provides a valid and reliable estimate of patients' average number of steps per day [15] and of energy expenditure [47] during slow and normal walking speed in a laboratory setting [48].

In summary, we found that physical activity in patients with COPD is independently associated with the 6-minute walking distance (6MWD), the number of stands during the STST, the total energy expenditure assessed by the self-reported physical activity questionnaire ( $\left.\mathrm{TEE}_{\mathrm{ZPAQ}}\right)$. These simple tests cannot be used to identify patients with an extremely inactive lifestyle.

\section{Author Contributions}

Conceived and designed the experiments: AJRvG EWR MK. Performed the experiments: AJRvG CFG ACS VAR NAS GG. Analyzed the data: AJRvG GFG ACS VAR NAS GG EWR MK. Contributed reagents/ materials/analysis tools: AJRvG EWR MK. Wrote the paper: AJRvG MK.

4. Garcia-Aymerich J, Lange P, Benet M (2006) Regular physical activity reduces hospital admission and mortality in chronic obstructive pulmonary disease: a population based cohort study. Thorax 61: 772-778.

5. Bourbeau J (2009) Activities of life: the COPD patient. COPD 6(3): 192-200.

6. Global Initiative for Chronic Obstructive Lung Disease (2004) Global strategy for the diagnosis, management and prevention of chronic obstructive pulmonary disease- executive summary. Heart, Lung, and Blood Institute, World Health Organization; COPD 1(1): 105-41, 103-104. 
7. Montoye HJ (2000) Introduction: evaluation of some measurements of physical activity and energy expenditure. Med Sci Sports Exerc 32(9): 439-441.

8. Shephard RJ, Vuillemin A (2003) Limits to the measurement of habitual physical activity by questionnaires * Commentary. Br J Sports Med 37: 197-206.

9. Pitta F, Troosters T, Probst VS, Spruit MA, Decramer M, et al. (2006) Quantifying physical activity in daily life with questionnaires and motion sensors in COPD. Eur Respir J 27: 1040-1055.

10. Kocks JWWH, Asijee GM, Tsiligianni IG, Kerstjens HAM, van der Molen T (2011) Functional status measurement in COPD: a review of available methods and their feasibility in primary care. Prim Care Respir J 20(3): 269-275.

11. Bossenbroek L, de Greef MHG, Wempe JB, Krijnen WP, ten Hacken NHT (2011) Daily Physical Activity in Patients with Chronic Obstructive Pulmonary Disease: A Systematic Review. COPD. DOI: 10.3109/15412555.2011.578601.

12. Miller MR, Hankinson J, Brusasco V (2005) Series "ATS/ERS Task Force: Standardisation of spirometry. Eur Respir J 26: 319-338.

13. Miller MR, Crapo R, Hankinson J, Brusasco V, Burgos F, et al. (2005) General considerations for lung function testing. Eur Respir J 26: 153-161.

14. Troosters T, Sciurba F, Battaglia S, Langer D, Valluri SR, et al. (2010) Physical inactivity in patients with COPD, a controlled multi-center pilot-study. Respiratory Medicine 104(7): 1005-1011.

15. Watz H, Waschki B, Boehme C, Claussen M, Meyer T, et al. (2008) Extrapulmonary effects of chronic obstructive pulmonary disease on physical activity: a cross-sectional study. Am J Respir Crit Care Med 177: 743-751.

16. Manini TM, Everhart JE, Patel KV, et al. (2006) Daily activity energy expenditure and mortality among older adults. JAMA 296: 171-179.

17. Black AE, Coward WA, Cole TJ, Prentice AM (1996) Human energy expenditure in affluent societies: an analysis of 574 doubly-labelled water measurements. Eur J Clin Nutr 50: 72-92.

18. American Thoracic Society (2002) ATS Statement: Guidelines for the SixMinute Walk Test. Am. J. Respir Crit Care Med 166: 111-117.

19. Dourado VZ, Antunes LC, Tanni SE, de Paiva SA, Padovani CR, et al. (2006) Relationship of Upper-Limb and Thoracic Muscle Strength to 6-min Walk Distance in COPD Patients. Chest 129(3): 551-557.

20. Slinde F, Ellegard L, Gronberg AM, Larsson S, Rossander-Hulthen L (2003) Total energy expenditure in underweight patients with severe chronic obstructive pulmonary disease living at home. Clin Nutr 22: 159-165.

21. (2008) Zutphen Physical Activity Questionnaire. Z Gerontol Geriat 41: 208-216.

22. Durnin JVGA, Passmore R (1967) Energy, Work and Leisure. Heinemann, London, GB.

23. Jacobs DR (1997) Minnesota Leisure-Time Physical Activity Questionnaire. Medicine and Science in Sports and Exercise 29(6): 62-72.

24. Folsom AR, Jacobs DR, Caspersen CJ, Gomez-Marin O, Knudsen J (1986) Test-retest reliability of the Minnesota Leisure Time Physical Activity Questionnaire. Journal of Chronic Diseases 39: 505-511.

25. Poulain M, Durand F, Palomba B, Ceugniet F, Desplan J, et al. (2003) 6-Minute Walk Testing Is More Sensitive Than Maximal Incremental Cycle Testing for Detecting Oxygen Desaturation in Patients With COPD. Chest 123(5): 14011407.

26. Rocco CC, Sampaio LM, Stribulov R, Correa JC (2011) Neurophysiological aspects and their relationship to clinical and functional impairment in patients with chronic obstructive pulmonary disease. Clinics 66(1): 125-129.

27. Cote CG, Casanova C, Marin JM, Lopez MV, Pinto-Plata V, et al. (2008) Validation and comparison of reference equations for the 6 -min walk distance test. Eur Respir J 31(3): 571-578.

28. Steele BG, Holt L, Belza B, Ferris S, Lakshminaryan S, et al. Quantifying physical activity in COPD using a triaxial accelerometer. Chest 2000; 117 : 1359-1367.
29. Troosters T, Gosselink R, Decramer M (1999) Six minute walking distance in healthy elderly subjects. Eur Respir J 14: 270-274.

30. Coronado M, Janssens JP, deMuralt B, Terrier P, Schutz Y, et al. (2003) Walking activity measured by accelerometry during respiratory rehabilitation. J Cardiopulm Rehabil 23(5): 357-364.

31. Pitta F, Takaki MY, Oliveira NH, Sant'anna TJ, Fontana AD, et al. (2008) Relationship between pulmonary function and physical activity in daily life in patients with COPD. Respir Med 102(8): 1203-1207.

32. Gross MM, Stevenson PJ, Charette SL, Pyka G, Marcus G (1998) Effect of muscle strength and movement speed on the biomechanics of rising from a chair in healthy elderly and young women. Gait Posture 8: 175-185.

33. Canuto FF, Rocco CC, Canuto FF, Rocco CC, de Andrade DV, et al, (2010) Neurophysiological comparison between the Sit-to-Stand test with the 6-Minute Walk test in individuals with COPD. Electromyogr Clin Neurophysiol 50(1): 4753.

34. Ozalevli S, Ozden A, Itil O, Akkoclu A (2007) Comparison of the Sit-to-Stand Test with 6 min walk test in patients with chronic obstructive pulmonary disease. Respir Med 101(2): 286-293.

35. Ward DS, Evenson KR, Vaughn A, Rodgers AB, Troiano RP (2005) Accelerometer use in physical activity: best practices and research recommendations. Med Sci Sports Exerc 37: 582-588.

36. Shephard RJ (2003) Limits to the measurement of habitual physical activity by questionnaires. Br J Sports Med 37: 197-206.

37. Steele BG, Holt L, Belza B, Ferris S, Lakshminaryan S, et al. (2000) Quantitating physical activity in COPD using a triaxial accelerometer. Chest 117: 1359-1367.

38. Pitta F, Troosters T, Spruit MA, Decramer M, Gosselink R (2005) Activity monitoring for assessment of physical activities in daily life in patients with chronic obstructive pulmonary disease. Arch Phys Med Rehabil 86: 1979-1985.

39. Baranowski T, Dworkin RJ, Cieslik CJ, Hooks P, Clearman DR, et al. (1984) Reliability and validity of self report of aerobic activity: family health project. Res Q 55: 309-317.

40. Giantomaso T, Makowsky L, Ashworth NL, Sankaran R (2003) The validity of patient and physician estimates of walking distance. Clin Rehabil 17: 394-401.

41. Adams SA, Matthews CE, Ebbeling CB, Moore CG, Cunningham JE, et al. (2005) The effect of social desirability and social approval on self-reports of physical activity. Am J Epidemiol 161(4): 389-398.

42. Cavalheri V, Donária L, Ferreira T, Finatti M, Camillo CA, et al. (2011) Energy expenditure during daily activities as measured by two motion sensors in patients with COPD. Respir Med 105(6): 922-929.

43. Garcia-Aymerich J, Farrero E, Felez MA, Izquierdo J, Marrades RM, et al. (2003) Risk factors of readmission to hospital for a COPD exacerbation: a prospective study. Thorax 58: 100-105.

44. Tudor-Locke C, Bassett DR Jr (2004) How many steps/day are enough? Preliminary pedometer indices for public health. Sports Med 34(1): 1-8.

45. Bravata DM, Smith-Spangler C, Sundaram V, Gienger AL, Lin N, et al. (2007) Using pedometers to increase physical activity and improve health: a systematic review. JAMA 298: 2296-2304.

46. Light RW, Merrill EJ, Despars JA (1985) Prevalence of depression and anxiety in patients with COPD: relationship to functional capacity. Chest 87: 35-38.

47. Jakicic JM, Marcus M, Gallagher KI, Randall C, Thomas E, et al. (2004) Evaluation of the SenseWear Pro Armband to assess energy expenditure during exercise. Med Sci Sports Exerc 36: 897-904.

48. Patel SA, Benzo RP, Slivka WA, Sciurba FC (2007) Activity monitoring and energy expenditure in COPD patients: a validation study. COPD 4: 107-112. 